\title{
W7-X NBI Beam Dump Thermocouple Measurements as Safety Interlock
}

\author{
Paul van Eeten, J.P. Kallmeyer, P. McNeely, N. Rust, D. Hartmann, J. Schacht, D. Naujoks, \\ S. Degenkolbe, R. Vilbrandt, H.S. Bosch and the W7-X Team
}

The Wendelstein 7-X stellarator started its first operational phase in October 2015 at the Max-Planck-Institute for Plasma Physics in Greifswald with the goal to verify that a stellarator magnetic confinement concept is a viable option for a fusion power plant.

In the operational phase OP1.2b of the Wendelstein 7-X stellarator in 2018 the Neutral Beam Injection (NBI) Heating System is operational. Any un-absorbed heating power is dumped on the NBI beam dump graphite tiles that are cooled using CuCrZr-cooling structures. The Heat Shield Thermography (HST) system is used to prevent damage and overheating of the graphite tiles on these beam dumps. In addition, other interlocks (plasma density and ECRH stray radiation interlocks among others) are present to prevent damage to in-vessel components in case of un-absorbed heating power. Since the HST as well as the other interlocks have a rather low safety integrity level (SIL) it was decided to use the available thermocouple measurements of the beam dumps as an additional interlock. Due to the relatively slow response of this type of measurement, the focus of this safety interlock lies on preventing major damage to the plasma vessel (PV) wall in case of a chain of malfunctions of HST, other heating interlocks and heating systems control. It is not implemented to fully prevent damage to the beam dump structure itself.

This paper describes the setup of the beam dump measurements, the upgrade of the electronics cabinets to SIL2-rated thermocouple measurement with alarm trip relays, the sequence for stopping the NBI beam and the analyses performed to determine the interlock alarm trip settings for operation in OP1.2b.

Keywords: Wendelstein 7-X, Commissioning, Operation, NBI, Instrumentation, Safety Interlock

\section{Introduction}

In the third operational phase of W7-X, OP1.2b, Neutral Beam Injection (NBI) is operational. W7-X has two NBIboxes in the W7-X half modules 20 and 21 [1], [2]. Each box has the capacity to be equipped with $4 \mathrm{RF}$ ion sources of $2.5 \mathrm{MW}(\mathrm{D} 0,60 \mathrm{kV})$ or $1.7 \mathrm{MW}(\mathrm{H} 0,55 \mathrm{kV})$ neutral power per source and a maximum pulse-length of $10 \mathrm{~s}$.

Box 20 is still in assembly. Box 21 is commissioned. For OP1.2b two sources per box are in operation, being sources 7 and 8 in HM21 (Fig. 1, HM = half module). In a later stage, two more beams per box will become available.

Depending on the absorption of the NBI beam energy into the plasma, a part of the beam will continue through to hit the inner first wall of the W7-X plasma vessel (PV), see Fig. 2. This shine through depends largely on the plasma density. Power loads of up to $39 \mathrm{MW} / \mathrm{m}^{2}$ for $\mathrm{H} 2$ operation can be deposited in these areas. To be able to handle these heat loads special beam dump tiles have been installed (Fig. 3). These tiles consist of a graphite front plate bolted to a CuCrZr-body, which is water cooled [3]. The structure is brazed to the steel water pipe for support.

To enable safe operation of the NBI, W7-X includes a heat shield thermography (HST) diagnostic that monitors the surface temperature of the graphite in the beam dump region. It is part of a local NBI fast interlock $(<50 \mathrm{~ms})$ system for shutting down the NBI in case of overheating of the beam dump, failure of the injector and beam blockage in the duct.

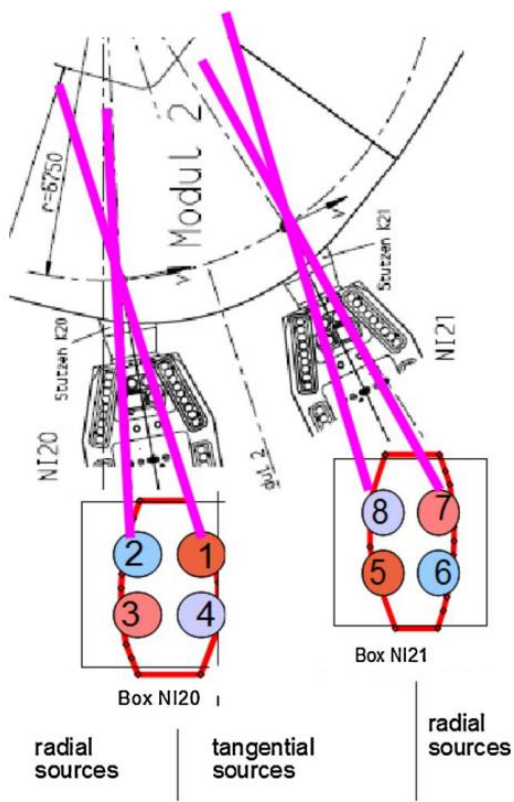

Fig. 1 Top view of NBI source positions on W7-X

This works in parallel to the central Fast Interlock system (cFIS) [4] that includes the plasma density using the single channel interferometer, the diamagnetic energy as well as sniffer probes for detecting ECRH stray radiation. This cFIS will shutdown both plasma heating systems (ECRH and NBI).

From the start of W7-X operation, it was foreseen to instrument the NBI beam dumps with thermocouples (TC) on the CuCrZr-body. Fig. 4 shows an overview of the beam dump diagnostics including the HST 
(monitoring the front side of the graphite tiles) and the beam dump TC (monitoring the back side of the $\mathrm{CuCrZr}$ heat sink).

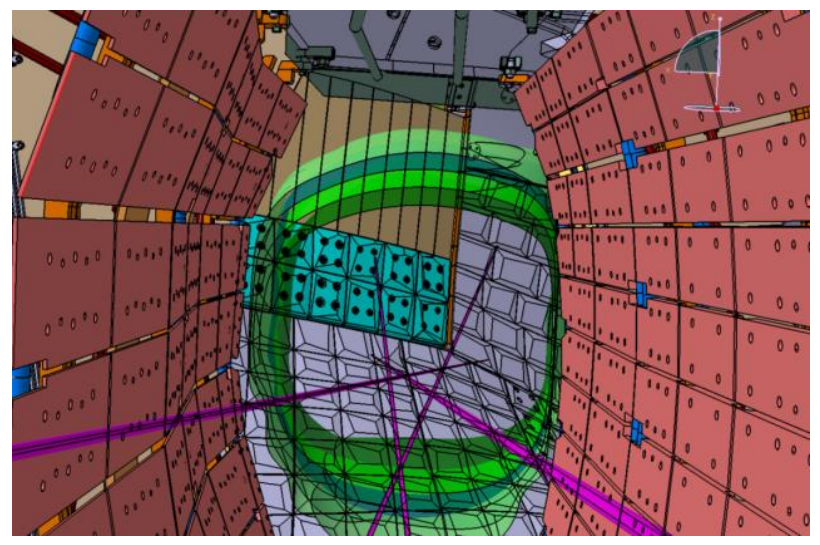

Fig. 2 NI21 beam paths for all 4 beams onto beam dump region (baffle and heat shield tiles) seen from Port AEK21

The TC were initially not planned to be used for an automatic interlock. The safety analysis [4] has shown that the HST alone does not provide the required safety level. Failure of the HST could result in overheating and destruction of the beam dumps.

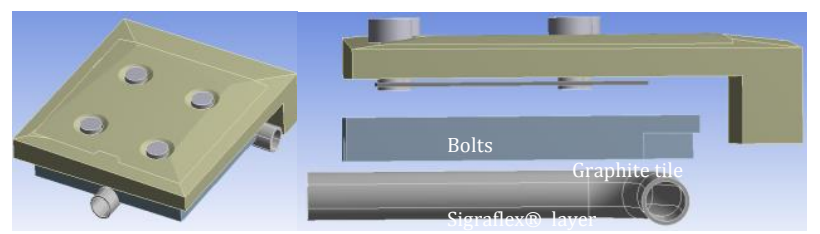

Fig. 3 Exploded view of typicai bean dump

The main risk when overloading the beam dump lies at the brazed connection of the CuCrZr-body to the steel water pipe. This connection both ensures proper cooling of the beam dump as well as provides the support for the beam dump segment and should stay below $500^{\circ} \mathrm{C}$. Higher temperatures could damage these connections and even result in de-bonding and subsequent release of the entire beam dump. When all other interlocks are failing the NBI beam would then start to heat the exposed PV wall and the thermal insulation within the cryostat, which should be avoided at all costs. A repair of the beam dump is cumbersome but possible. This is not the case for the PV wall and the cryostat components.

To provide a safety backup for this worst-case scenario it was decided to use the beam dump TC as an NBI interlock. In each HM eight thermocouples have been installed. For each of the four central regions of the beam strike points on the first wall, two TC are positioned on the backside of these beam dump tiles to provide redundancy in these measurements.

\section{Safety architecture}

The initial signal chain (Fig. 5 a) shows the TC $\mathrm{mV}$ output being transferred and converted into a ${ }^{\circ} \mathrm{C}$ for archiving. The AD-converter had no SIL-rating. The safety analysis required a SIL2-rating for the signal chain to provide adequate reliability.

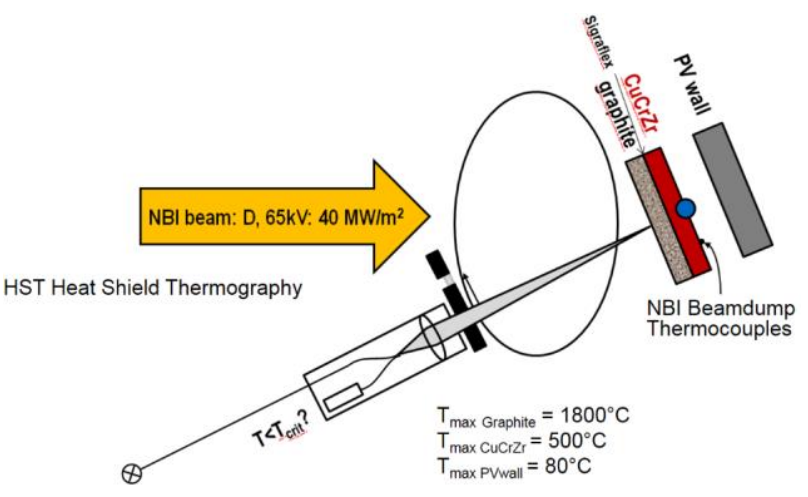

Fig. 4 Scheme of NBI beam dump safety diagnostics

A $2^{\text {nd }}$ SIL2-rated AD-converter was added to provide the status signal for the W7-X central Safety System (cSS) [5]. The cSS triggers the shutdown of the HV power switches that power both the NBI as well as the Electron Cyclotron Resonance Heating System (ECRH).

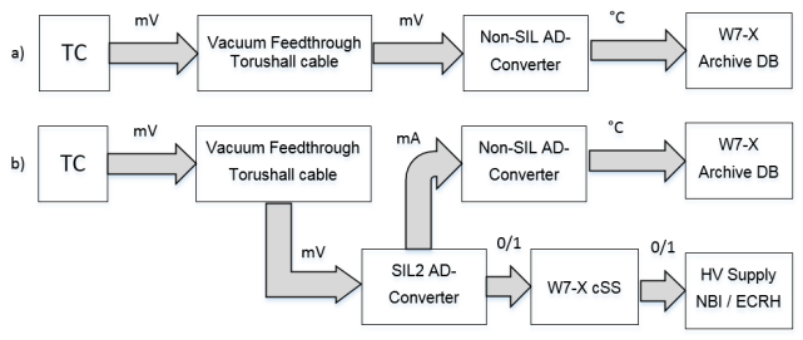

Fig. 5 Signal chain a) old setup b) SIL2 setup

The TC have also been subjected to a safety analysis. This W7-X Safety Integrated Function (SIF-A-00037) is a SIF with a low demand, e.g. the SIF is expected to be triggered less than once a year. Therefore, the probability of failure on demand (PFD) has to be analysed. For the TC as used (Type $\mathrm{N}$ ), no failure rates are provided by the manufacturer. In [6] the TC has a failure rate of $\lambda=1 \mathrm{e}^{-6} / \mathrm{h}$. This is equal to SIL 1 for single channel systems. As each monitored beam dump has two TC the safety analysis declares these sensors to be redundant. Of all 214 TC within W7-X, over the first two years of operation only one TC failed. This was caused by assembly activities and is not deemed a dangerous undetected failure.

The SIL2 AD-converter also monitors the state of the TC measurement regarding Sensor Burnout, Sensor out of configured range, Analog output saturation and internal module fault. Combined with the redundant TC measurement for each beam dump the measurement chain fulfills the requirements for a SIL 2 rating. A validation of this safety function is required for each experiment phase or at least once a year.

\section{Temperature Limit and Time Requirements}

The HST diagnostic provides a fast interlock as its chain of sensor, logic and actors enables a shutdown of the NBI beam within $50 \mathrm{~ms}$. This is not the case for the beam dump TC. Heat load on the front face of the graphite will take several seconds before it initiates a temperature rise at the $\mathrm{TC}$ on the backside of the CuCrZR-body. 


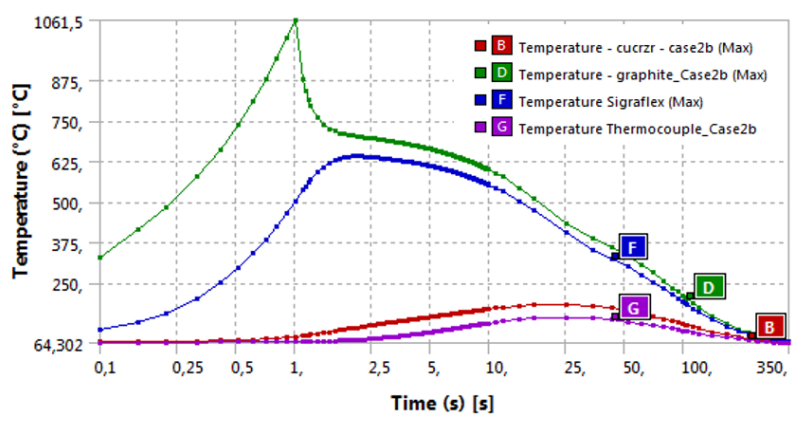

Fig. 6 Maximum Temperatures during typical NBI Pulse with HST reacting at $1000^{\circ} \mathrm{C}$

The time line in Fig. 6 shows clearly that, as the peak temperature of the graphite (D) for this load case develops within 1 sec., the CuCrZr-body temperature (B) rises much slower and peaks roughly 20 seconds later. This time delay needs to be taken into account when determining a proper limit for the interlock using these TC. The temperature limit should be set as low as possible to reduce the risk of damage when the fast interlock system is failing without intervening unwantedly during normal operation.

Since the beam dump including TC have been installed before the previous campaign a change of the TC position (ideally on the graphite) would have required a large effort in personnel and time regarding dismantling, rerouting and re-assembly of the beam dump and its TC. For the W7-X OP1.2b campaign with NBI, it was therefore important to use the TC in their current position.

The NBI team has created a list of plausible heating scenarios to be analyzed regarding thermal response of the beam dump. For the thermal mechanical analyses, finite element models (FEM) of typical beam dumps have been created. These models were then subjected to the loads and boundary conditions as shown in Table 1, which covers the situation where either the maximum pulse duration of $7 \mathrm{sec}$. or the HST intervenes. The reaction time for the HST-driven NBI HV-shutdown is $\sim 50 \mathrm{~ms}$.
The scenarios assume different plasma densities resulting in different shine through fractions and thus different power loads on the beam dump tiles. Case $2 \mathrm{a}$ up to $5 \mathrm{~b}$ created [7].

Case 6 and 7 cover the situation where a full collapse of the plasma resulting in a $100 \%$ shine through is assumed both for $50 \mathrm{~ms}$ as well as for $100 \mathrm{~ms}$ (slightly different and slower signal chain within NBI and HV-System).

The reaction time of the interlock chain from TC until NBI HV-shutdown was estimated to be:

$\mathrm{RT}_{\mathrm{TC}}+\left(\mathrm{RT}_{\mathrm{cSS}}+\mathrm{RT}_{\mathrm{HV}}\right)=\sim 100 \mathrm{~ms}+\sim 400 \mathrm{~ms}=\sim 0.5 \mathrm{sec}$

The reaction time (RT) from the TC-measurement up to the interlock signal for the cSS was tested and confirmed. The actual time to shut down the high voltage (HV) still needs confirmation but a realistic assumption is $400 \mathrm{~ms}$ for $\mathrm{RT}_{\mathrm{cSS}}+\mathrm{RT}_{\mathrm{HV}}$. For providing a suitable temperature limit of the $\mathrm{TC}$, this reaction time has to be taken into account. During that time, the beam continues to load the beam dump. Fig. 7 shows the relation between the TC temperature limit and the final temperature of the beam dump interlayer between graphite and $\mathrm{CuCrZr}$ at NBI shutdown for different reaction times, in this case assuming $16 \mathrm{MW}$ of beam power. The data shown in Fig. 7 involved the non-cooled situation. For the initial response (ramp up) of the temperature during an NBI pulse, this does not make a big difference compared to a cooled beam dump. As an example take the curve "300 ms / 100\% 16 MW no cooling / Tmax Interface”. Fig. 7 shows that for a $300 \mathrm{~ms}$ total reaction time, the interlock should trigger at $\mathrm{TC}_{\text {limit }}$ of $350^{\circ} \mathrm{C}$ to make sure that $\mathrm{T}_{\text {max }}$ at the interlayer does not exceed $500^{\circ} \mathrm{C}$ at the time the NBI beam is switched off. $\mathrm{A} \mathrm{T}_{\text {avg }}$ of $500^{\circ} \mathrm{C}$ increases the $\mathrm{TC}_{\text {limit }}$ as it allows for local spots being $500^{\circ} \mathrm{C}$. It is important to note that the $\mathrm{CuCrZr}$ temperature will continue to rise (overshoot) even after shutdown since the heat energy wave propagating from the front side of the graphite to back-end of the $\mathrm{CuCrZr}$ will take much longer.

\begin{tabular}{|c|c|c|c|c|c|c|c|}
\hline \# & $\begin{array}{l}\text { Shine } \\
\text { through }\end{array}$ & $\begin{array}{l}\text { Power- } \\
\text { density } \\
{\left[\mathrm{MW} / \mathrm{m}^{2}\right.}\end{array}$ & $\begin{array}{l}\text { Duration } \\
\text { NBI[s] }\end{array}$ & $\begin{array}{l}\mathbf{T}_{\text {ambient }} \\
{\left[{ }^{\circ} \mathbf{C}\right]}\end{array}$ & $\begin{array}{l}\mathbf{T}_{\text {Graphite }} \\
(\mathbf{t}=\mathbf{0}) \\
{\left[{ }^{\circ} \mathrm{C}\right]}\end{array}$ & $\begin{array}{l}\mathbf{T}_{\mathrm{CuCrZr}} \\
(\mathbf{t}=\mathbf{0}) \\
{\left[{ }^{\circ} \mathrm{C}\right]}\end{array}$ & $\begin{array}{l}\text { Comments } \\
\mathrm{T}_{\text {graphite }}=\text { Max. Temperature on the graphite Tile } \\
\mathrm{T}_{\mathrm{CuCrZr}}=\text { Max. Temperature on } \mathrm{CuCrZr} \text { cooling body }\end{array}$ \\
\hline 1 & 0 & 0,0083 & 0 & 20 & 20 & 20 & Plasmaoperation with average convective load in OP1.2. No NBI \\
\hline $2 \mathrm{a}$ & $65 \%$ & 13,24 & 7 & 200 & \multirow{10}{*}{$\begin{array}{l}\mathrm{T}_{\text {Graphite }} \text { : } \\
\text { Graphite } \\
\text { Temperature } \\
\text { at start of } \\
\text { analysis } \\
\text { based on } \\
\text { equilibrium } \\
\text { temperature } \\
\text { distribution } \\
\text { coming from } \\
\text { Case 1 }\end{array}$} & \multirow{10}{*}{$\begin{array}{l}\mathrm{T}_{\mathrm{CuCrZr}} \text { : } \\
\text { CuCrZr heat } \\
\text { sink } \\
\text { Temperature } \\
\text { at start of } \\
\text { analysis } \\
\text { based on } \\
\text { equilibrium } \\
\text { temperature } \\
\text { distribution } \\
\text { coming from } \\
\text { Case 1 }\end{array}$} & Plasma Density $2,5 \cdot 10^{19} \mathrm{~m}^{-3}$ \\
\hline $2 \mathrm{~b}$ & $65 \%$ & 13,24 & 7 & 200 & & & $\begin{array}{l}\text { Plasma Density } 2,5 \cdot 10^{19} \mathrm{~m}^{-3} \text {; Beam duration: time point } \\
\left.\mathrm{t}\left(\mathrm{T}_{\text {graphite }}=1000^{\circ} \mathrm{C}\right)+0,05 \mathrm{~s}\right) \text { or } \max 7 \mathrm{sec} .\end{array}$ \\
\hline $3 a$ & $33 \%$ & 6.72 & 7 & 200 & & & Plasma Density $5 \cdot 10^{19} \mathrm{~m}^{-3}$ \\
\hline $3 b$ & $33 \%$ & 6.72 & 7 & 200 & & & $\begin{array}{l}\text { Plasma Density } 5 \cdot 10^{19} \mathrm{~m}^{-3} ; \text { Beam duration: time point } \\
\left.\mathrm{t}\left(\mathrm{T}_{\text {graphite }}=1000^{\circ} \mathrm{C}\right)+0,05 \mathrm{~s}\right) \text { or } \max 7 \mathrm{sec} \text {. }\end{array}$ \\
\hline $4 \mathrm{a}$ & $20 \%$ & 4,07 & 7 & 200 & & & Plasma Density $7.5 \cdot 10^{19} \mathrm{~m}^{-3} ;$ Beam $7 \mathrm{sec}$ \\
\hline $4 \mathrm{~b}$ & $20 \%$ & 4,07 & 7 & 200 & & & $\begin{array}{l}\text { Plasma Density } 7.5 \cdot 10^{19} \mathrm{~m}^{-3} ; \text { Beam duration: time point } \\
\left.\mathrm{t}\left(\mathrm{T}_{\text {graphite }}=1000^{\circ} \mathrm{C}\right)+0,05 \mathrm{~s}\right) \text { or } \max 7 \mathrm{sec} .\end{array}$ \\
\hline $5 \mathrm{a}$ & $12 \%$ & 2,44 & 7 & 200 & & & Plasma Density $1.0 \cdot 10^{20} \mathrm{~m}^{-3}$ \\
\hline $5 b$ & $12 \%$ & 2,44 & 7 & 200 & & & $\begin{array}{l}\text { Plasma Density } 1.0 \cdot 10^{20} \mathrm{~m}^{-3} ; \text { Beam duration: time point } \\
\left.\mathrm{t}\left(\mathrm{T}_{\text {graphite }}=1000^{\circ} \mathrm{C}\right)+0,05 \mathrm{~s}\right) \text { or } \max 7 \mathrm{sec} .\end{array}$ \\
\hline 6 & $65 \%$ & 13,24 & 7 & 200 & & & $\begin{array}{l}\text { As } 2 \mathrm{a} \text {, but at } \mathrm{t}\left(\mathrm{T}_{\text {graphite }}=1000^{\circ} \mathrm{C}\right) \text { plasma collaps with NBI beam } \\
\text { firing additional } 50 \mathrm{msec} \text { with } 100 \% \text { shine through: } 0.77 * 26,45 \\
\mathrm{MW} / \mathrm{m}^{2}=20,37 \mathrm{MW} / \mathrm{m}^{2}\end{array}$ \\
\hline 7 & $65 \%$ & 13,24 & 7 & 200 & & & $\begin{array}{l}\text { As 2a, but at } \mathrm{t}\left(\mathrm{T}_{\text {graphite }}=1000^{\circ} \mathrm{C}\right) \text { plasma collaps with NBI beam } \\
\text { firing additional } 100 \mathrm{msec} \text { with } 100 \% \text { shine through: } 0.77 * 26,45 \\
\mathrm{MW} / \mathrm{m}^{2}=20,37 \mathrm{MW} / \mathrm{m}^{2}\end{array}$ \\
\hline
\end{tabular}

Table 1 List of NBI operation scenarios (NBI operation in hydrogen) 
This overshoot could still result in significant damage to the beam dump. For the sole goal of protecting the PV wall it is important though, that the NBI beam is shut down before this occurs. Since at the time the safety system was being planned, no experience with operating the NBI in W7-X was gathered, it was decided to start with a conservative setting of the TC interlock temperature limit. Any change of settings requires a new validation of all $16 \mathrm{TC}$ channels for both half modules. This was taken into consideration for the decision. The FE analyses showed that a setting of $150^{\circ} \mathrm{C}$ should ensure that even the overshoot temperature at the $\mathrm{CuCrZr}$-Interlayer stays below $500^{\circ} \mathrm{C}$ in case of fast interlock failure even at pulses with full shine through. This minimizes the risk of damage to the beam dump. In operation, it still has to be verified that this limit does not intervene with normal operation.

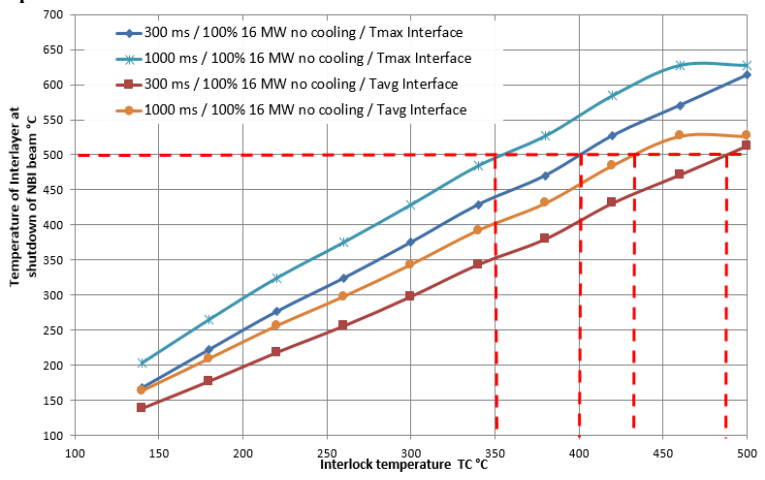

Fig. 7 Relation between TC temperature limit and NBI shutdown temperature of the interlayer depending on NBI power density $\left(\mathrm{MW} / \mathrm{m}^{2}\right)$ and total reaction time.

\section{Conclusion and outlook}

For OP1.2b the NBI beam dump TC interlock was established to protect the PV wall in case of a fast interlock failure. Initially the temperature limit is set to $150^{\circ} \mathrm{C}$ to prevent major damage even to the beam dump. Operation has to show whether this setting intervenes with normal operation. It is also required to verify the thermal response as measured in the machine compared to the FEM predictions. The experience gathered in OP1.2b will be used to optimize the safety system towards steady state operation in OP2 with all 8 NBI beam sources active.

Using the direct TC temperature value for the interlock introduces a strong lag in reacting to the heat load on the graphite tile. Calculating the temperature gradient can aid in detecting high shine through power loads much earlier. Fig. 8 shows both the absolute temperature and the temperature gradient for 2.4 and $25 \mathrm{MW} / \mathrm{m}^{2}$ power densities. Where the absolute temperatures take several seconds to noticeably diverge from each other, the temperature gradient is already diverging strongly within the second. The temperature gradient of the beam dump TC could thus be used to effectively protect the beam dump. The challenge is to find a robust signal chain (sensor/logic/actor) that accommodates a calculation of the rate of change during a pulse. The SIL2-rated ADconverters used for the current setup do not allow for assessing the rate of change of the TC temperature. It would require a more complex logic that is also more prone to failure. Another option would be to use the NONSIL AD-converters (Fig. 5). These converters have the ability to calculate rates of change and compare it to a defined limit. That status output can then be forwarded to the cSS in parallel to the SIL2-signal to provide an additional, albeit less reliable, interlock for the NBI. This has to be decided based on the experience gathered in OP1.2b.

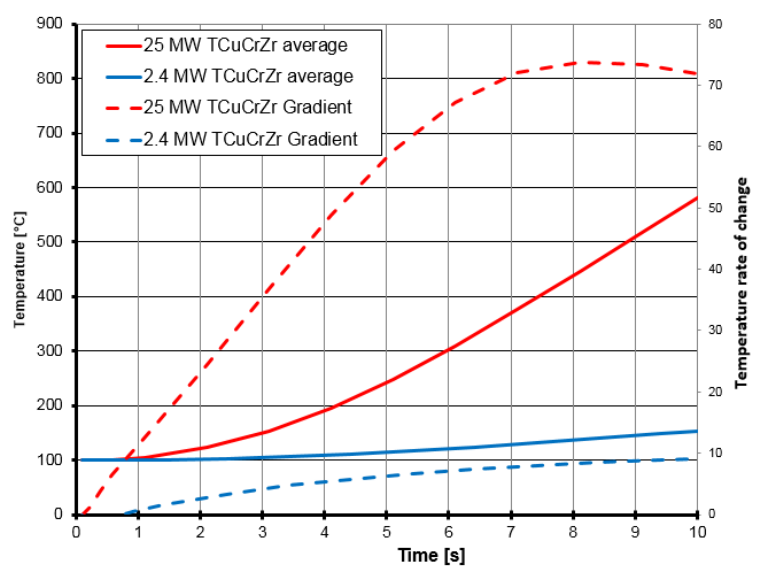

Fig. 8 Example of thermal gradient for two extreme NBI beam dump power densities $\left(\mathrm{MW} / \mathrm{m}^{2}\right)$

\section{Acknowledgments}

The author would like to thank all contributors to the development of this NBI safety interlock. This work has been carried out within the framework of the EUROfusion Consortium and has received funding from the Euratom research and training programme 2014-2018 under grant agreement No 633053. The views and opinions expressed herein do not necessarily reflect those of the European Commission.

\section{References}

[1] P. McNeely et al., "Current status of the neutral beam heating system of W7-X”, Fusion Engineering and Design, Volume 88, October 2013, Pages 1034-1037.

[2] N. Rust et al., "W7-X neutral-beam-injection: Selection of the NBI source positions for experiment start-up", Fusion Engineering and Design, Volume 86, October 2011, Pages $728-731$.

[3] B. Mendelevitch et al., "Water-cooling system of the W7$\mathrm{X}$ plasma facing components", Fusion Engineering and Design, Volume 98-99, October 2015, Pages 1235-1238.

[4] R Vilbrandt et al., "First version of the W7-X Fast Interlock System", presented at the 30th Symposium on Fusion Technology (SOFT), Giardini Naxos, Italy, 16th Sept. 2018.

[5] A. Werner, et al., "Development and commissioning of the Wendelstein 7-X safety control system", 29th Symposium on Fusion Technology (SOFT 2016) (2017).

[6] Cadwallader, L. C. (1996). "Reliability estimates for selected sensors in fusion applications", INEL-96/0295, Idaho National Engineering Laboratory.

[7] Boscary J. et al (2011), "Design and technological solutions for the plasma facing components of W7-X", Fusion Eng. Des. 86 572-5. 